\title{
ANALISIS FAKTOR PENDORONG DAN PENGHAMBAT PENGEMBANGAN AGRIBISNIS PERIKANAN TANGKAP DENGAN PENDEKATAN SUBSISTEM DI KABUPATEN PENAJAM PASER UTARA
}

\author{
Novita Putri Setiawati ${ }^{1}$ \\ Dwiana Novianti tufail ${ }^{2}$ \\ Devi Triwidya Sitaresmi ${ }^{3}$ \\ Program Studi Perencanaan Wilayah dan Kota, Institut Teknologi Kalimantan ${ }^{1,2,3}$ \\ Penulis Korespondensi e-mail: iamnovitaputri@gmail.com ${ }^{1}$
}

\begin{abstract}
The marine fishery production of Penajam Paser Utara was 6,045 tons per year of 2018 which was close to the national production number. In addition, fishery is a leading sector after agriculture in PPU which will be developed, the fisheries sector should be able to contribute to a large GDP as well, but this was not in line because seeing the contribution of the fisheries sector to GRDP, constant prices from 2012 to 2016 have decreased by 12,760.03 million rupiah. The purpose of this research is to determine the driving factors and inhibiting factors for the development of fisheries capture agribusiness. This was certainly supported by the direction of Spatial Plans of Penajam Paser Utara Regency in 2011-2031, namely realizing the Regency as the center of agribusiness. The methods used in this research were content analysis to identify driving and inhibiting factors of fisheriescatching agribusiness. The results obtained were as many as 21 variables were the driving factors for agribusiness development and 1 additional variable as an inhibiting factor namely the quality of the Fish Auction Place or TPI.
\end{abstract}

Keywords: Regional Development, Fisheries Capture Agribusiness, Subsystem.

\section{ABSTRAK}

Hasil produksi perikanan laut PPU sebesar 6.045 ton per tahun 2018 yang mendekati angka produksi nasional. Selain itu perikanan merupakan sektor unggulan setelah pertanian di PPU yang akan dikembangkan, seharusnya sektor perikanan mampu memberikan sumbangan terhadap PDRB yang besar pula, namun hal tersebut tidak sejalan karena melihat dari sumbangan sektor perikanan terhadap PDRB harga konstan dari tahun 2012 hingga tahun 2016 mengalami penurunan sebesar 12.760,03 juta rupiah. Tujuan dilakukannya penelitian ini adalah untuk mengetahui faktor pendorong dan faktor penghambat pengembangan agribisnis perikanan tangkap. Hal tersebut tentunya didukung oleh arahan RTRW Kabupaten Penajam Paser Utara tahun 2011-2031 yaitu mewujudkan Kabupaten sebagai pusat agribisnis. Adapun metode yang akan digunakan dalam penelitian ini yaitu content analysis untuk menganalisis faktor pendorong dan penghambat agribisnis perikanan tangkap. Hasil yang didapatkan adalah sebanyak 21 variabel merupakan faktor pendorong pengembangan agribisnis dan 1 variabel tambahan sebagai faktor penghambat yaitu kualitas Tempat Pelelangan Ikan atau TPI.

Kata kunci: Pengembangan Wilayah, Agribisnis Perikanan Tangkap, Subsistem. 
Jurnal Planologi Vol. 18 No. 1, April 2021

Available: http://jurnal.unissula.ac.id/index.php/psa

\section{PENDAHULUAN}

Berdasarkan data Kabupaten Penajam Paser Utara dalam angka tahun 2019, Penajam telah memproduksi perikanan laut sebesar 6.045 ton per tahun 2018. Perikanan tangkap di Kabupaten Penajam tentunya memiliki potensi yang cukup besar, karena wilayah ini berhadapan dengan Selat Makassar. Berdasarkan data statisitik perikanan dan kelautan Kabupaten Penajam Paser Utara tahun 2015, terdapat kurang lebih 53 jenis ikan laut produksi daerah yang tersebar di setiap Kecamatan pesisir, dengan jumlah produksi di Kecamatan Penajam sebesar 1.900,3 Ton, Kecamatan Waru sebesar 1.205,5 Ton, Kecamatan Babulu sebesar 1.169,7 Ton, dan Kecamatan Sepaku denganjumlah produksi 187,8 Ton. Dengan potensi Penajam sebagai kawasan pesisir yang mampu memproduksi perikanan setara dengan angka produksi nasional yang mencapai kurang lebih 6.000 ton per tahun dan merupakan sektor unggulan setelah pertanian di Penajam Paser Utara yang akan dikembangkan, seharusnya sektor perikanan mampu memberikan sumbangan terhadap PDRB yang besar pula, namun hal tersebut tidak sejalan karena melihat dari sumbangan sektor perikanan terhadap PDRB harga konstan dari tahun 2012 hingga tahun 2016 mengalami penurunan sebesar 12.760,03 juta rupiah. Berdasarkan permasalahan penurunan PDRB dari sektor perikanan, maka diperlukan upaya untuk meningkatkan kembali PDRB. Salah satu penyebab kurangnya sektor perikanan dalam memberikan sumbangan terhadap PDRB karena tidak didukung oleh ketersediaan lokasi pengelolaan dan pemasaran yang disediakan oleh pemerintah PPU, hal ini terbukti dalam indikasi program pada RZWP-3K Penajam Paser Utara, tidak menetapkan lokasi yang pasti terkait program yang telah dibuat diantaranya seperti 1) Program Optimalisasi Pengelolaan dan Pemasaran Produksi Perikanan, dan 2) Pembangunan PPI dan TPI dan sarana prasarana pendukungnya. Untuk itu diperlukan adanya pengembangan kawasan perikanan untuk meningkatkan pendapatan dari sektor perikanan dengan konsep agribisnis dimana agribisnis merupakan suatu sistem yang terdiri atas subsistem hulu, usaha tani, hilir, dan penunjang, mulai dari produksi, pengolahan, pemasaran atau kegiatan lain yang berkaitan (Hastuti, 2017). Selain itu menurut Yasmin (2017) bidang agribisnis memiliki cakupan yang luas dari hulu ke hilir sehingga banyak pilihan usaha yang bisa dibuat, dan produk - produk agribisnis merupakan kebutuhan primer manusia sehingga akan selalu dibutuhkan. Hal tersebut tentunya didukung oleh arahan RTRW Kabupaten Penajam tahun 2011-2031 yaitu mewujudkan Kabupaten sebagai

pusat agribisnis dan agroindustri yang berbasis pada ekonomi kerakyatan. Selain itu konsep

Novita Putri Setiawati, Dwiana Novianti Tufail, Devi Triwidya Sitaresmi 2 Analisis Faktor Pendorong Dan Penghambat ... 
agribisnis perikanan juga tertuang dalam tujuan RZWP-3K PPU tahun 2015-2035 yaitu “Terwujudnya Wilayah Pesisir dan Pulau-Pulau Kecil Kabupaten Penajam Paser Utara Sebagai Pusat Agribisnis dan Industri Maritim yang Berbasis Pada Ekonomi Kerakyatan yang Berkelanjutan”. Untuk itu perlu diketahui terlebih dahulu faktor pendorong dan faktor penghambat pengembangan dalam agribisnis perikanan tangkap.

\section{METODOLOGI}

Dalam penelitian ini digunakan teknik pengumpulan data dengan wawancara dan observasi melalui survei primer dengan sampel yang digunakan adalah teknik purposive sampling dengan menetapkan kriteria-kriteria tertentu yang harus dipenuhi oleh sampelsampel yang digunakan dalam penelitian. Sampel berupa Informan kunci pelaku agribisnis di lokasi sampel (Rasmikayati dkk, 2017). Sedangkan teknik analisis yang digunakan adalah content analysis dengan melakukan pengumpulan data berupa wawancara stakeholder, melakukan pengkodean hasil wawancara, kemudian melakukan pengelompokan kata kunci dan mendeskripsikan hasil (Arbani, 2017 dan Diinillah, 2017). Adapun stakeholder terkait yang memiliki nilai kepentingan tinggi terkait agribisnis perikanan tangkap diantaranya :

a) Kepala Dinas Perikanan Kabupaten Penajam Paser Utara

b) Ketua Kelompok Perikanan KUB (Kelompok Usaha Bersama) Kabupaten Penajam Paser Utara

c) Ketua Kelompok Perikanan POKLAHSAR (Pengolah dan Pemasar) Kabupaten Penajam Paser Utara.

Adapun kode yang akan digunakan adalah sebagai berikut.

Tabel 1. Kode Stakeholders

\begin{tabular}{|c|c|c|}
\hline \multicolumn{2}{|c|}{ Kode } & \multirow{2}{*}{ Stakeholder } \\
\hline Huruf & Angka & \\
\hline $\mathrm{G}$ & 1 & $\begin{array}{c}\text { Kepala Dinas Perikanan Kabupaten Penajam } \\
\text { Paser Utara }\end{array}$ \\
\hline $\mathrm{M}$ & 1 & Ketua Kelompok Perikanan KUB \\
\hline M & 2 & Ketua Kelompok Perikanan POKLAHSAR \\
\hline
\end{tabular}

Tabel 2. Kode Variabel Identifikasi Faktor Pendorong

\begin{tabular}{|c|c|c|c|}
\hline \multicolumn{3}{|c|}{ Kode } & \multirow{2}{*}{$\begin{array}{c}\text { Variabel Identifikasi Faktor } \\
\text { Pendorong }\end{array}$} \\
\hline Huruf & Angka & Kalimat ke- $n$ & \\
\hline $\mathrm{C}$ & 1 & \multirow{4}{*}{$\begin{array}{c}\text { Merupakan kode } \\
\text { kalimat yang telah } \\
\text { diucapkan stakeholder } \\
\text { dengan urutan ke } n\end{array}$} & Kapal Penangkapan Ikan \\
\hline $\mathrm{C}$ & 2 & & Alat-alat Penangkapan Ikan \\
\hline $\mathrm{C}$ & 3 & & Komoditas \\
\hline $\mathrm{C}$ & 4 & & Industri Makanan \\
\hline
\end{tabular}


Jurnal Planologi Vol. 18 No. 1, April 2021

Available: http://jurnal.unissula.ac.id/index.php/psa

\begin{tabular}{cccc}
\hline & Kode & & $\begin{array}{c}\text { Variabel Identifikasi Faktor } \\
\text { Pendorong }\end{array}$ \\
\hline Huruf & Angka & Kalimat ke- n & Pengeringan \\
\hline $\mathrm{C}$ & 5 & & Pembekuan \\
\hline $\mathrm{C}$ & 6 & & Pasar Tradisional \\
\hline $\mathrm{C}$ & 7 & & Pemasar Ikan/Tengkulak \\
\hline $\mathrm{C}$ & 8 & & Lembaga Penyuluh \\
\hline $\mathrm{C}$ & 9 & & Lembaga Keuangan \\
\hline $\mathrm{C}$ & 10 & & Lembaga Pemerintah \\
\hline $\mathrm{C}$ & 11 & & Transportasi \\
\hline $\mathrm{C}$ & 12 & & \\
\hline $\mathrm{C}$ & 13 & & \\
\hline
\end{tabular}

Sumber : Diinilah 2017 dengan modifikasi penulis, 2020

Tabel 3. Kode Variabel Identifikasi Faktor Penghambat

\begin{tabular}{|c|c|c|c|}
\hline \multicolumn{3}{|c|}{ Kode } & \multirow{2}{*}{$\begin{array}{c}\text { Variabel Identifikasi Faktor } \\
\text { Penghambat }\end{array}$} \\
\hline Huruf & Angka & Kalimat ke- n & \\
\hline $\mathrm{F}$ & 1 & \multirow{13}{*}{$\begin{array}{l}\text { Merupakan kode } \\
\text { kalimat yang telah } \\
\text { diucapkan stakeholder } \\
\text { dengan urutan ke n }\end{array}$} & Kapal Penangkapan Ikan \\
\hline $\mathrm{F}$ & 2 & & Alat-alat Penangkapan Ikan \\
\hline $\mathrm{F}$ & 3 & & Komoditas \\
\hline $\mathrm{F}$ & 4 & & Industri Makanan \\
\hline $\mathrm{F}$ & 5 & & Pengeringan \\
\hline $\mathrm{F}$ & 6 & & Pembekuan \\
\hline $\mathrm{F}$ & 7 & & Pasar Tradisional \\
\hline $\mathrm{F}$ & 8 & & Pemasar Ikan/Tengkulak \\
\hline $\mathrm{F}$ & 9 & & Lembaga Penyuluh \\
\hline $\mathrm{F}$ & 10 & & Lembaga Keuangan \\
\hline $\mathrm{F}$ & 11 & & Lembaga Pemerintah \\
\hline $\mathrm{F}$ & 12 & & Transportasi \\
\hline $\mathrm{F}$ & 13 & & Koperasi Agribisnis \\
\hline
\end{tabular}

Sumber : Diinilah 2017 dengan modifikasi penulis, 2020

Tabel 4. Kode Variabel Tambahan Sebagai Faktor Pendorong dan Faktor Penghambat

\begin{tabular}{|c|c|c|c|}
\hline \multicolumn{3}{|c|}{ Kode } & \multirow{2}{*}{ Variabel Tambahan } \\
\hline Huruf & Angka & Kalimat ke- n & \\
\hline $\mathrm{T}$ & 1 & \multirow{2}{*}{$\begin{array}{c}\text { Merupakan kode } \\
\text { kalimat yang telah } \\
\text { diucapkan stakeholder } \\
\text { dengan urutan ke } \mathrm{n}\end{array}$} & $\begin{array}{c}\text { Variabel Tambahan Faktor } \\
\text { Pendorong }\end{array}$ \\
\hline $\mathrm{T}$ & 2 & & $\begin{array}{c}\text { Variabel Tambahan Faktor } \\
\text { Penghambat }\end{array}$ \\
\hline
\end{tabular}

Sumber : Diinilah 2017 dengan modifikasi penulis, 2020

\section{HASIL DAN PEMBAHASAN}

Berikut ini ditampilkan hasil analisis faktor pendorong dan faktor penghambat pengembangan subsistem. Dimana identifikasi ini dilakukan menggunakan metode content analysis kuantitatif yang dapat menjelaskan masalah dengan hasil yang digeneralisasikan mewakili seluruh populasi (Rahmat, 2006). Dalam melakukan analisis ini telah ditentukan 
terlebih dahulu variabel yang telah didapatkan dari teori terkait agribisnis perikanan tangkap yang kemudian digunakan untuk dilakukan penelitian diantaranya :

a. kualitas kapal penangkapan ikan dan jumlah kapal penangkapan ikan (Intyas dan Zainal 2013)

b. kualitas alat penangkapan ikan dan jumlah alat penangkapan ikan (Intyas dan Zainal, 2013 dan Koestiono dan Hardana 2018)

c. komoditas (Hermawan, 2006 dan Kusnadi, dkk 2017)

d. industri makanan (Nainggolan dan Johndikson, 2012)

e. pengeringan (Hermawan, 2006)

f. pembekuan (Hermawan, 2006)

g. kualitas pasar tradisional dan jumlah pasar tradisional (Kusnadi dkk, 2017)

h. jumlah pemasar ikan/tengkulak (Intyas dan Zainal, 2013)

i. kualitas lembaga keuangan dan jumlah lembaga keuangan (Intyas dan Zainal, 2013 dan Koestiono dan Hardana 2018)

j. kualitas lembaga penyuluh dan jumlah lembaga penyuluh (Koestiono dan Hardana 2018)

k. kualitas lembaga pemerintah dan jumlah lembaga pemerintah (Hermawan, 2006)

1. kualitas transportasi dan jumlah transportasi (Hermawan, 2006)

m. kualitas koperasi agribisnis dan jumlah koperasi agribisnis (Hermawan, 2006 dan Intyas dan Zainal, 2013).

Dilakukan dengan mewawancarai para stakeholders untuk kemudian dilakukan perekaman terhadap hasil wawancara yang akan ditulis menjadi sebuah transkrip dan diberikan kode untuk memudahkan dalam mengidentifikasi faktor pendorong dan faktor penghambat dari pengembangan agribisnis perikanan tangkap.

\begin{tabular}{|c|c|c|c|c|}
\hline Variabel & Stakeholder & Sumber Teks & Kode & $\begin{array}{c}\text { Penjelasan Variabel } \\
\text { Terkonfirmasi }\end{array}$ \\
\hline $\begin{array}{c}\text { Kualitas Kapal } \\
\text { Penangkapan } \\
\text { Ikan }\end{array}$ & G1 & $\begin{array}{l}\text { Nah kapal-kapal ini adalah } \\
\text { sarana untuk mereka } \\
\text { melakukan penangkapan } \\
\text { ikan dilaut. Ini menjadi faktor } \\
\text { pendukung terkait dengan } \\
\text { peningkatan produksi } \\
\text { perikanan tangkap kita di laut } \\
\text { Penajam Paser Utara. }\end{array}$ & $\mathrm{C} 1.1$ & $\begin{array}{lr}\text { Terkonfirmasi } & \text { bahwa } \\
\text { kualitas } & \text { Kapal } \\
\text { penangkapan } & \text { ikan } \\
\text { merupakan sarana } & \text { untuk } \\
\text { mendapatkan } & \text { ikan } \\
\text { tangkapan di } & \text { laut. } \\
\text { Sehingga keberadaan } \\
\text { kapal penangkapan ikan }\end{array}$ \\
\hline
\end{tabular}


Jurnal Planologi Vol. 18 No. 1, April 2021

Available: http://jurnal.unissula.ac.id/index.php/psa

\begin{tabular}{|c|c|c|c|c|}
\hline Variabel & Stakeholder & Sumber Teks & Kode & $\begin{array}{c}\text { Penjelasan Variabel } \\
\text { Terkonfirmasi }\end{array}$ \\
\hline & G1 & $\begin{array}{l}\text { Jadi kapal itu, sarana itu, } \\
\text { nelayan itu merupakan } \\
\text { faktor } \\
\text { pembangunan perikanan di } \\
\text { Kabupaten Penajam Paser } \\
\text { Utara, bukan faktor } \\
\text { penghambat ya faktor } \\
\text { pendorong. Faktor pemicu } \\
\text { untuk meningkatkan produksi } \\
\text { perikanan tangkap di Penajam } \\
\text { Paser Utara. }\end{array}$ & $\mathrm{C} 1.2$ & $\begin{array}{l}\text { sangat membantu dalam } \\
\text { pengadaan produksi ikan } \\
\text { dan dapat menunjang } \\
\text { pembangunan perikanan } \\
\text { di Kabupaten Penajam } \\
\text { Paser Utara. }\end{array}$ \\
\hline & G1 & $\begin{array}{l}\text { Sarana kapal ditempat kita ada } \\
\text { juga yang memiliki kapal } \\
\text { dibawah } 3 \text { Groston kapal } \\
\text { ketinting baik itu yang punya } \\
\text { mesin maupun yang tidak } \\
\text { punya mesin. Kapal yang } \\
\text { dibawah } 5 \text { groston itu juga } \\
\text { dimiliki oleh teman-teman kita } \\
\text { di Penajam Paser Utara. Ada } \\
\text { juga kapal yang 5-10 Groston } \\
\text { ada juga yang 10-20 Groston } \\
\text { ada juga yang } 30 \text { Groston } \\
\text { keatas }\end{array}$ & $\mathrm{C} 1.6$ & \\
\hline & G1 & $\begin{array}{l}\text { Nah untuk kapal-kapal } \\
\text { dengan kapasitas yang saya } \\
\text { sebutkan tadi itu memang } \\
\text { merupakan daya dorong } \\
\text { untuk peningkatan produksi } \\
\text { perikanan tangkap di } \\
\text { Kabupaten Penajam Paser } \\
\text { Utara }\end{array}$ & $\mathrm{C} 1.7$ & \\
\hline & \multirow{2}{*}{ M1 } & Ya mendorong lah & $\mathrm{C} 1.4$ & \\
\hline & & Iya & $\mathrm{C} 1.5$ & \\
\hline & & $\begin{array}{lll}\text { Sehingga } & \text { mereka } & \text { dalam }\end{array}$ & & Terkonfirmasi \\
\hline $\begin{array}{c}\text { Jumlah Kapal } \\
\text { Penangkapan } \\
\text { Ikan }\end{array}$ & G1 & $\begin{array}{l}\text { mendapatkan ikan ini } \\
\text { tentunya harus diiringi } \\
\text { dengan peningkatan sarana } \\
\text { kapalnya, peningkatan } \\
\text { prasarananya terkait dengan } \\
\text { alat -alat tangkap. }\end{array}$ & $\mathrm{C} 1.3$ & $\begin{array}{lr}\text { dengan peningkatan } \\
\text { jumlah } & \text { kapal } \\
\text { penangkapan ikan dapat } \\
\text { menghasilkan jumlah } \\
\text { produksi yang lebih } \\
\text { banyak lagi. }\end{array}$ \\
\hline \multirow{2}{*}{$\begin{array}{l}\text { Kualitas Alat } \\
\text { Penangkapan } \\
\text { Ikan }\end{array}$} & G1 & $\begin{array}{l}\text { Iya, mereka memiliki kapal } \\
\text { tentunya mereka juga } \\
\text { memiliki alat tangkap untuk } \\
\text { mendapatkan itu. }\end{array}$ & $\mathrm{C} 2.1$ & \multirow{2}{*}{$\begin{array}{lr}\text { Terkonfirmasi } & \text { bahwa } \\
\text { semua jenis } & \text { alat-alat } \\
\text { penangkapan ikan sebagai } & \text { dalam } \\
\text { prasarana } & \text { ikan }\end{array}$} \\
\hline & M1 & $\begin{array}{l}\text { mendapatkan itu. } \\
\text { Iya betul itu mendorong, } \\
\text { ibaratnya membantu gitu kan? }\end{array}$ & $\mathrm{C} 2.3$ & \\
\hline
\end{tabular}


Jurnal Planologi Vol. 18 No. 1, April 2021




Jurnal Planologi Vol. 18 No. 1, April 2021

Available: http://jurnal.unissula.ac.id/index.php/psa




Jurnal Planologi Vol. 18 No. 1, April 2021

Available: http://jurnal.unissula.ac.id/index.php/psa

\begin{tabular}{|c|c|c|c|c|}
\hline Variabel & Stakeholder & Sumber Teks & Kode & $\begin{array}{c}\text { Penjelasan Variabel } \\
\text { Terkonfirmasi }\end{array}$ \\
\hline & & $\begin{array}{l}\text { hanya di Penajam tapi } \\
\text { pasarnya rata-rata ada di } \\
\text { luar Penajam Paser Utara }\end{array}$ & & \\
\hline & M2 & Iya banyak yang mau & C4.10 & \multirow{4}{*}{$\begin{array}{l}\text { Terkonfirmasi bahwa } \\
\text { pengeringan merupakan } \\
\text { salah satu teknik yang } \\
\text { digunakan dalam } \\
\text { mengolah hasil perikanan } \\
\text { yang digunakan dalam } \\
\text { industri pembuatan } \\
\text { makanan hasil olahan } \\
\text { laut, salah satunya dengan } \\
\text { penjemuran ikan asin. } \\
\text { Selain itu kebutuhan } \\
\text { masyarakat akan ikan asin } \\
\text { kering cukup tinggi, } \\
\text { sehingga pengeringan } \\
\text { sangat mempengaruhi } \\
\text { peningkatan produksi } \\
\text { ikan asin. }\end{array}$} \\
\hline \multirow{4}{*}{$\begin{array}{l}\text { Teknik } \\
\text { Pengeringan }\end{array}$} & M2 & $\begin{array}{l}\text { cuman yang sisa-sisa yang } \\
\text { sudah tidak bisa dijual kami } \\
\text { belah dijemur. }\end{array}$ & C5.1 & \\
\hline & \multirow[b]{2}{*}{ M2 } & $\begin{array}{l}\text { sedangkan kemarin-kemarin } \\
\text { mba kan seminggu yang lalu } \\
\text { baru dijemur setengah kering } \\
\text { itu sudah diangkut semua, } \\
\text { karena memang katanya } \\
\text { kebutuhan pasar lebih besar. }\end{array}$ & & \\
\hline & & & C5.2 & \\
\hline & M2 & $\begin{array}{l}\text { Jadi kadang itu kalau betul- } \\
\text { betul tidak ada panas sama } \\
\text { sekali kadang direndamin di } \\
\text { air garam } 2 \text { hari baru } \\
\text { dijemur. Karena kalau tidak } \\
\text { mba pasti dibusukin lalat } \\
\text { beulat semua kayak gitu, } \\
\text { karena kan betul-betul kita kan } \\
\text { pakainya garam aja, tidak pakai } \\
\text { yang disemprot atau yang } \\
\text { gimana kan }\end{array}$ & F5.1 & $\begin{array}{l}\text { Terkonfirmasi bahwa } \\
\text { terdapat kerugian dalam } \\
\text { proses pengeringan akibat } \\
\text { pembusukan produk ikan } \\
\text { kering yang tidak dapat } \\
\text { dijemur karena kondisi } \\
\text { cuaca yang mendung. }\end{array}$ \\
\hline \multirow[b]{2}{*}{$\begin{array}{c}\text { Teknik } \\
\text { Pembekuan }\end{array}$} & G1 & $\begin{array}{l}\text { Iya Iya, jadi mereka sangat } \\
\text { membutuhkan alat-alat } \\
\text { proses atau alat penunjang } \\
\text { produksi. Dimana mereka juga } \\
\text { perlu sarana prasarana } \\
\text { pengolahan ikan, terutama } \\
\text { produk amplang ya }\end{array}$ & C6.1 & \multirow{2}{*}{$\begin{array}{l}\text { Terkonfirmasi bahwa } \\
\text { pembekuan merupakan } \\
\text { salah satu teknik yang } \\
\text { digunakan bagi para } \\
\text { pengolah di industri } \\
\text { makanan terutama yang } \\
\text { memproduksi makanan } \\
\text { berupa cemilan seperti } \\
\text { amplang. Produk ikan } \\
\text { yang akan diolah } \\
\text { membutuhkan sebuah alat } \\
\text { pembekuan untuk tempat } \\
\text { penyimpanan sementara } \\
\text { sebelum dilakukan } \\
\text { pengolahan. }\end{array}$} \\
\hline & M2 & $\begin{array}{l}\text { Iya, kalau seperti bahan } \\
\text { bakunya } \\
\text { mungkin ya itukan memang } \\
\text { kalau untuk satu dua ekor } \\
\text { mungkin dibekukan dulu } \\
\text { nanti ada tambahannya baru } \\
\text { diolah }\end{array}$ & C6.2 & \\
\hline $\begin{array}{c}\text { Kualitas Pasar } \\
\text { Tradisional }\end{array}$ & G1 & $\begin{array}{l}\text { Untuk pasar lokal disini saya } \\
\text { pikir semuanya juga sebagian }\end{array}$ & C7.2 & $\begin{array}{l}\text { Terkonfirmasi bahwa } \\
\text { kualitas pasar tradisional }\end{array}$ \\
\hline
\end{tabular}


Jurnal Planologi Vol. 18 No. 1, April 2021

Available: http://jurnal.unissula.ac.id/index.php/psa

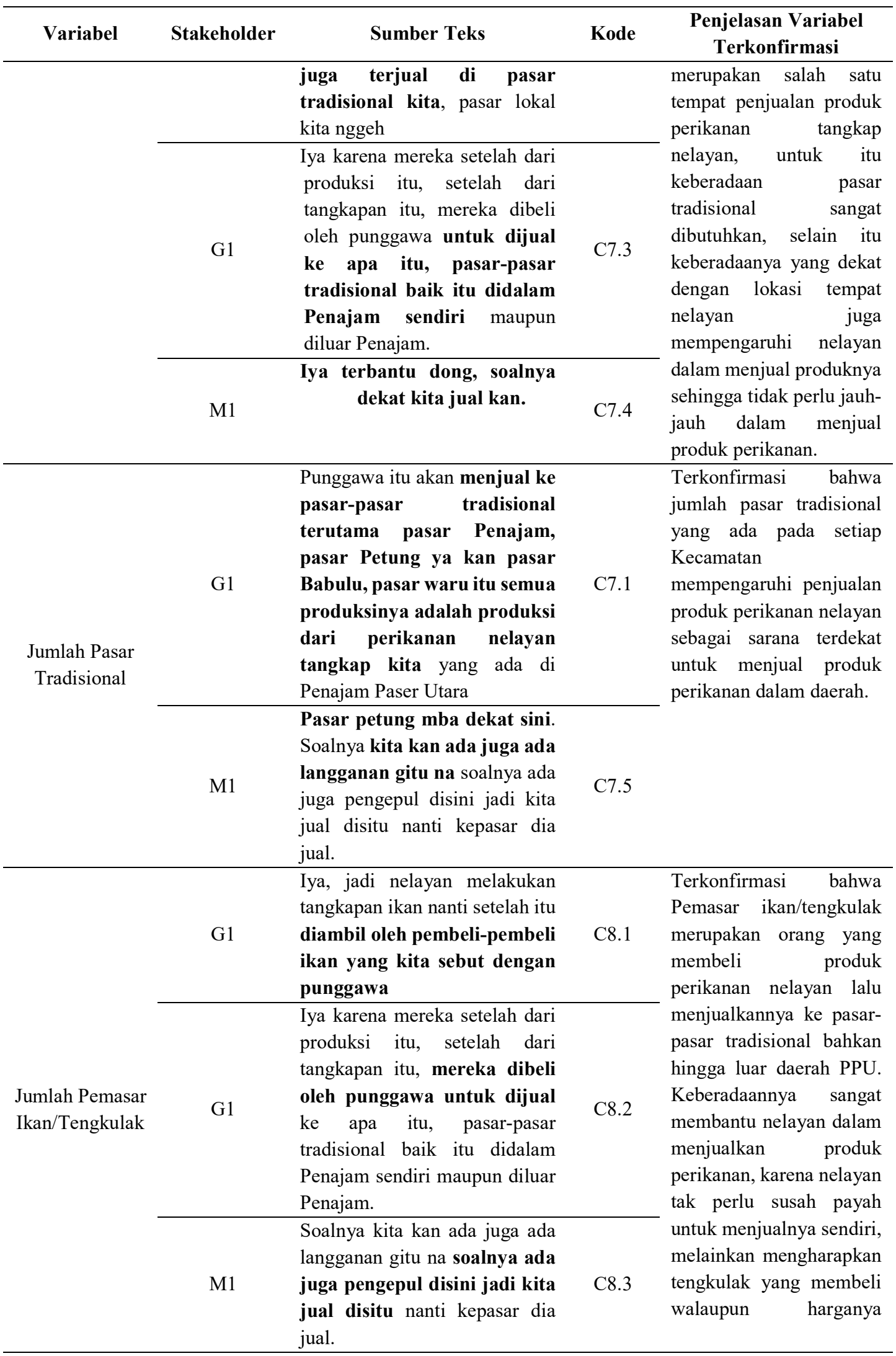


Jurnal Planologi Vol. 18 No. 1, April 2021

Available: http://jurnal.unissula.ac.id/index.php/psa

\begin{tabular}{|c|c|c|c|c|}
\hline Variabel & Stakeholder & Sumber Teks & Kode & $\begin{array}{c}\text { Penjelasan Variabel } \\
\text { Terkonfirmasi }\end{array}$ \\
\hline & M1 & $\begin{array}{l}\text { Iya terbantu soalnya } \\
\text { ibaratnya itu nda jauh jauh } \\
\text { kita jual kan nggak lari } \\
\text { kesana kesini. Kalau ada } \\
\text { tengkulak kan langsung jual } \\
\text { ikan. }\end{array}$ & C8.4 & $\begin{array}{l}\text { murah namun juga tidak } \\
\text { merugikan. }\end{array}$ \\
\hline & M1 & $\begin{array}{l}\text { ya ibaratnya ga merugikan } \\
\text { juga lah, dari pada kita jual } \\
\text { sendiri kan }\end{array}$ & C8.5 & \\
\hline & M1 & $\begin{array}{l}\text { Ya itu, kalau jual kepasar kan } \\
\text { kita lari-lari kesana, kalau } \\
\text { pengepul kan langsung dia } \\
\text { yang ngambil. }\end{array}$ & C8.6 & \\
\hline \multirow{3}{*}{$\begin{array}{l}\text { Kualitas } \\
\text { Lembaga } \\
\text { Keuangan }\end{array}$} & G1 & $\begin{array}{l}\text { Mereka bisa meminjam } \\
\text { disalah satu pihak perbankan } \\
\text { untuk kebutuhan sarana } \\
\text { prasarana nya dan mereka } \\
\text { mengembangkan dengan sistim } \\
\text { apa itu perputaran ekonomi } \\
\text { mereka bisa berjalan }\end{array}$ & C9.2 & \multirow{3}{*}{$\begin{array}{l}\text { Terkonfirmasi bahwa } \\
\text { kualitas lembaga } \\
\text { keuangan mempengaruhi } \\
\text { daya tumbuh kelompok } \\
\text { nelayan karena dapat } \\
\text { membantu memberikan } \\
\text { pinjaman modal kepada } \\
\text { para nelayan dalam } \\
\text { mengembangkan } \\
\text { usahanya terutama dalam } \\
\text { pemeliharaan sarana dan } \\
\text { prasarana yang dimiliki. }\end{array}$} \\
\hline & M1 & Iya membantu & C9.3 & \\
\hline & G1 & $\begin{array}{l}\text { perbankan } r \text { pernah } \\
\text { membantu beberapa } \\
\text { kelompok-kelompok kita } \\
\text { pembudidaya termasuk juga } \\
\text { keramba jarring apung } \\
\text { bahkan nilainya cukup tinggi } \\
\text { sampai } 400 \text { sampai } 500 \text { juga } \\
\text { dia pinjamkan }\end{array}$ & C9.4 & \\
\hline \multirow{2}{*}{$\begin{array}{c}\text { Jumlah } \\
\text { Lembaga } \\
\text { Keuangan }\end{array}$} & \multirow{2}{*}{ G1 } & $\begin{array}{l}\text { Iya, lembaga keuangan mikro, } \\
\text { perbankan, ataupun lembaga- } \\
\text { lembaga keuangan lainnya itu } \\
\text { sangat-sangat mempengaruhi } \\
\text { daya kembang daya }\end{array}$ & \multirow{2}{*}{ C9.1 } & \multirow{2}{*}{$\begin{array}{l}\text { Terkonfirmasi bahwa } \\
\text { jumlah lembaga keuangan } \\
\text { seperti perbankan yang } \\
\text { ada di setiap Kecamatan } \\
\text { memiliki pengaruh } \\
\text { terhadap daya kembang } \\
\text { dan tumbuhnya kelompok } \\
\text { perikanan dari bantuan } \\
\text { yang diberikan. }\end{array}$} \\
\hline & & \begin{tabular}{ll} 
tumbuhnya & \multicolumn{2}{c}{ kelompok- } \\
kelompok & perikanan di \\
Kabupaten & Penajam Paser \\
Utara. &
\end{tabular} & & \\
\hline \multirow{3}{*}{$\begin{array}{l}\text { Kualitas } \\
\text { Lembaga } \\
\text { Penyuluh }\end{array}$} & G1 & $\begin{array}{lr}\text { Iya, jadi r } & \text { keberadaan } \\
\text { keberhasilan } & \text { sektor } \\
\text { perikanan itu tidak terlepas } \\
\text { dari kuncinya adalah }\end{array}$ & $\mathrm{C} 10.1$ & \multirow{3}{*}{$\begin{array}{l}\text { Terkonfirmasi bahwa } \\
\text { kualitas lembaga } \\
\text { penyuluh berperan aktif } \\
\text { dalam memberikan } \\
\text { informasi kepada nelayan } \\
\text { dan memberikan suluhan } \\
\text { serta pendampingan } \\
\text { untuk mendukung maju }\end{array}$} \\
\hline & & $\begin{array}{l}\text { kelembagaan penyuluhan } \\
\text { Kelompok-kelompok }\end{array}$ & & \\
\hline & G1 & $\begin{array}{l}\text { menggunakan akses informasi } \\
\text { itu dari teman-teman } \\
\text { penyuluh }\end{array}$ & C10.2 & \\
\hline
\end{tabular}


Jurnal Planologi Vol. 18 No. 1, April 2021

Available: http://jurnal.unissula.ac.id/index.php/psa

\begin{tabular}{|c|c|c|c|c|}
\hline Variabel & Stakeholder & Sumber Teks & Kode & $\begin{array}{c}\text { Penjelasan Variabel } \\
\text { Terkonfirmasi }\end{array}$ \\
\hline & G1 & $\begin{array}{l}\text { Jadi teman-teman penyuluh } \\
\text { memberikan informasi- } \\
\text { informasi dan mendampingi }\end{array}$ & $\mathrm{C} 10.3$ & $\begin{array}{l}\text { kembangnya } \\
\text { nelayan. }\end{array}$ \\
\hline & G1 & $\begin{array}{l}\text { Mereka tugasnya yang } \\
\text { mendampingi ran } \\
\text { memberikan informasi } \\
\text { suluhan-suluhan, sehingga } \\
\text { dengan maju kembangnya } \\
\text { kelompok ini terlepas dari } \\
\text { tugas-tugas penyuluh untuk } \\
\text { menyampaikan informasi } \\
\text { kepada masyarakat atau pelaku } \\
\text { usaha perikanan di Kabupaten } \\
\text { Penajam Paser Utara }\end{array}$ & C10.4 & \\
\hline & M1 & $\begin{array}{l}\text { Iya membantu soalnya kalau } \\
\text { ada info info itu cepat kita } \\
\text { tahu. }\end{array}$ & C10.5 & \\
\hline & G1 & $\begin{array}{l}\text { Namun demikian saat ini masih } \\
\text { semuanya bisa tercover } \\
\text { artinya masih bisa diatasi } \\
\text { oleh temen-temen penyuluh } \\
\text { dilapangan dari sektor } \\
\text { kelembagaan penyuluhan }\end{array}$ & C10.6 & \\
\hline \multirow{3}{*}{$\begin{array}{l}\text { Jumlah } \\
\text { Lembaga } \\
\text { Penyuluh }\end{array}$} & M1 & Ooh ada-ada itu & C10.7 & $\begin{array}{lr}\text { Terkonfirmasi } & \text { bahwa } \\
\text { jumlah lembaga penyuluh } \\
\text { terdapat di } \\
\text { Kecamatan } & \text { setiap } \\
\text { keberadaanya } & \text { membantu } \\
\text { nelayan } & \text { dalam } \\
\text { memberikan penyuluhan } \\
\text { dan informasi. }\end{array}$ \\
\hline & \multirow[b]{2}{*}{ G1 } & \multirow[t]{2}{*}{$\begin{array}{l}\text { Sayangnya } \\
\text { keterbatasan } \\
\text { penyuluh kami ini sangat } \\
\text { terbatas, ada } 5 \text { petugas } \\
\text { penyuluh kami yang terbagi } \\
\text { dimasing-masing Kecamatan }\end{array}$} & & \multirow{2}{*}{$\begin{array}{l}\text { Terkonfirmasi bahwa } \\
\text { terdapat keterbatasan } \\
\text { jumlah penyuluh yang } \\
\text { tersebar di setiap } \\
\text { Kecamatan yaitu hanya } 1 \\
\text { disetiap Kecamatan. } \\
\text { Namun hal tersebut tidak } \\
\text { membuat nelayan tidak } \\
\text { mendapat perhatian. } \\
\text { Namun memang terdapat } \\
\text { satu Kecamatan yang } \\
\text { tidak pernah menerima } \\
\text { penyuluhan terhadap } \\
\text { nelayan. }\end{array}$} \\
\hline & & & F10.1 & \\
\hline $\begin{array}{c}\text { Kualitas } \\
\text { Lembaga } \\
\text { Pemerintah } \\
\end{array}$ & G1 & $\begin{array}{l}\text { Kita akan bantu berdasarkan } \\
\text { kebutuhan dan berdasarkan } \\
\text { anggaran yang ada. }\end{array}$ & C11.2 & $\begin{array}{lr}\text { Terkonfirmasi } & \text { bahwa } \\
\text { kualitas } & \text { lembaga } \\
\text { pemerintah turut berperan }\end{array}$ \\
\hline
\end{tabular}


Jurnal Planologi Vol. 18 No. 1, April 2021

Available: http://jurnal.unissula.ac.id/index.php/psa

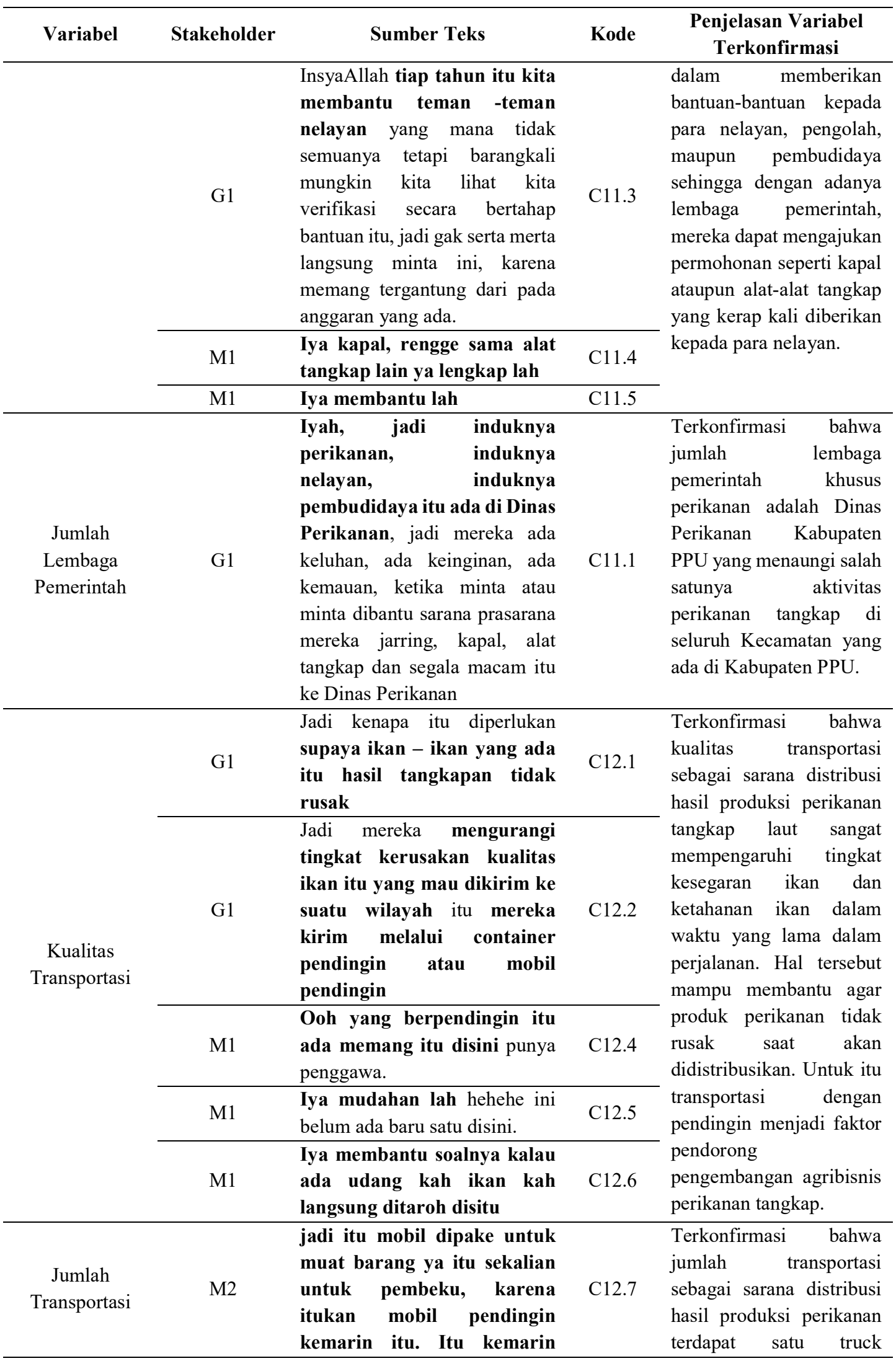


Jurnal Planologi Vol. 18 No. 1, April 2021

Available: http://jurnal.unissula.ac.id/index.php/psa

\begin{tabular}{|c|c|c|c|c|}
\hline Variabel & Stakeholder & Sumber Teks & Kode & $\begin{array}{c}\text { Penjelasan Variabel } \\
\text { Terkonfirmasi }\end{array}$ \\
\hline & & $\begin{array}{l}\text { dapatnya sekitar tahun } 2017 \\
2018\end{array}$ & & $\begin{array}{l}\text { dilengkapi dengan cold } \\
\text { storage yang terdapat di }\end{array}$ \\
\hline & G1 & $\begin{array}{l}\text { Kita punya mobil pendingin, } \\
\text { kita juga punya cold storage, } \\
\text { nah cold storage itu untuk } \\
\text { menyimpan ikan sehingga } \\
\text { mereka secara struktur tidak } \\
\text { rusak. }\end{array}$ & $\mathrm{C} 12.3$ & $\begin{array}{l}\text { koperasi perikanan sangat } \\
\text { membantu proses } \\
\text { distribusi. }\end{array}$ \\
\hline \multirow{7}{*}{$\begin{array}{l}\text { Kualitas } \\
\text { Koperasi } \\
\text { Agribisnis }\end{array}$} & G1 & $\begin{array}{l}\text { Ketika bantuan-bantuan pun } \\
\text { bisa jadi lewat koperasi, }\end{array}$ & C13.1 & \multirow{6}{*}{ 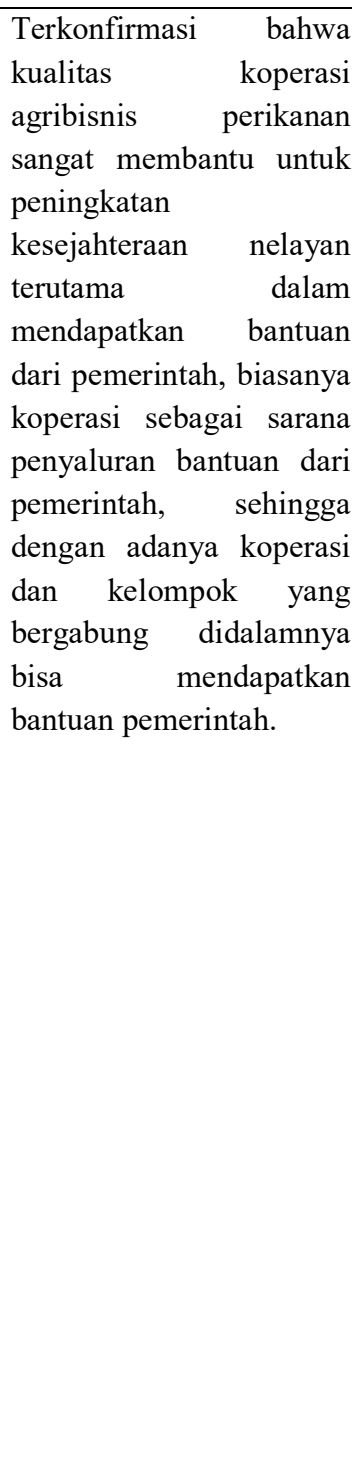 } \\
\hline & G1 & $\begin{array}{l}\text { Tujuan akhirnya adalah untuk } \\
\text { peningkatan kesejahteraan } \\
\text { anggota koperasi, dimana } \\
\text { anggota koperasi itu adalah } \\
\text { sebagian besar itu adalah } \\
\text { masyarakat-masyarakat yang } \\
\text { tergabung kedalam kelompok } \\
\text { usaha bersama artinya } \\
\text { kelompok nelayan gitu yah. }\end{array}$ & $\mathrm{C} 13.2$ & \\
\hline & G1 & $\begin{array}{l}\text { Jadi sangat diuntungkan } \\
\text { sekali ketika kelompok- } \\
\text { kelompok ingin bergabung } \\
\text { dengan koperasi-koperasi } \\
\text { perikanan }\end{array}$ & C13.4 & \\
\hline & \multirow[b]{2}{*}{ M2 } & $\begin{array}{l}\text { Jadi misalnya ada bantuan tapi } \\
\text { melalui koperasi ya sudah } \\
\text { dirapatkannya dirumah. }\end{array}$ & C13.5 & \\
\hline & & $\begin{array}{l}\text { Jadi semua kelompok yang } \\
\text { terdata, karena kan dari KKP } \\
\text { sendiri peraturan untuk } \\
\text { mendapatkan bantuan itu } \\
\text { kan harus melalui koperasi, } \\
\text { jadi semua kelompok harus } \\
\text { digabungkan di koperasi. }\end{array}$ & C13.6 & \\
\hline & M2 & $\begin{array}{l}\text { Nah jadi kayak kemarin itu } \\
\text { kelompok pak haji itu yang } \\
\text { lumayan sudah banyak dapat } \\
\text { itu, mulai dari perahu, mesin, } \\
\text { alat tangkap, pengganti troll, } \\
\text { pokoknya alat mancing rawe } \\
\text { itu banyak sudah mba } \\
\text { banyak }\end{array}$ & C13.8 & \\
\hline & M2 & $\begin{array}{l}\text { Belum, jadi kemarin itu cuman } \\
\text { modal solar pun cuman dari } \\
\text { ketentuan pokok bayar } \\
\text { anggota aja, jadi uang solar itu } \\
\text { ya teputar di uang anggota- } \\
\text { anggota yang masuk itu aja }\end{array}$ & F13.1 & $\begin{array}{lr}\text { Terkonfirmasi } & \text { bahwa } \\
\text { kualitas } & \text { koperasi } \\
\text { agribisnis } & \text { menurut } \\
\text { stakeholder } & \text { ketua } \\
\text { kelompok } & \text { perikanan } \\
\text { POKLAHSAR } & \text { bahwa } \\
\text { koperasi belum } & \text { berjalan } \\
\end{array}$ \\
\hline
\end{tabular}


Jurnal Planologi Vol. 18 No. 1, April 2021

\begin{tabular}{|c|c|c|c|c|}
\hline Variabel & Stakeholder & Sumber Teks & Kode & $\begin{array}{c}\text { Penjelasan Variabel } \\
\text { Terkonfirmasi }\end{array}$ \\
\hline & & & & $\begin{array}{l}\text { untuk melakukan simpan } \\
\text { pinjam melainkan jual } \\
\text { beli solar. Namun hal } \\
\text { tersebut tidak berlaku } \\
\text { pada semua koperasi, } \\
\text { terdapat juga koperasi } \\
\text { yang telah melakukan } \\
\text { kegiatan simpan pinjam. }\end{array}$ \\
\hline \multirow[t]{3}{*}{$\begin{array}{c}\text { Jumlah } \\
\text { Koperasi } \\
\text { Agribisnis }\end{array}$} & G1 & $\begin{array}{l}\text { Jadi koperasi disini ada } \\
\text { beberapa koperasi } 4 \text { atau } 5 \\
\text { koperasi yang sudah berdiri } \\
\text { baik itu kebutuhan sarananya, } \\
\text { baik itu kebutuhan solarnya, } \\
\text { baik itu kebutuhan-kebutuhan } \\
\text { yang terkait dengan hasil } \\
\text { tangkapnya itu koperasi punya } \\
\text { peran untuk mengendalikan. }\end{array}$ & $\mathrm{C} 13.3$ & \multirow[t]{3}{*}{ 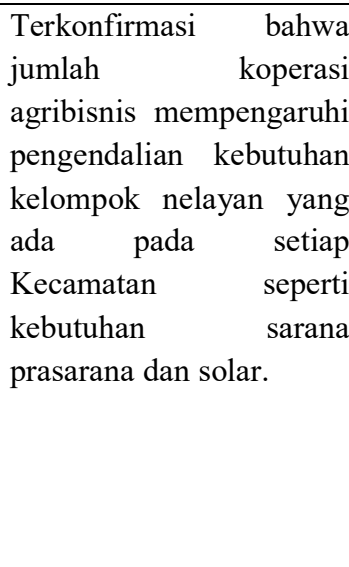 } \\
\hline & M2 & $\begin{array}{l}\text { Itu kelompoknya pak } \\
\text { kajena koperasi } \\
\text { kan } \\
\text { kegiatannya disitu }\end{array}$ & $\mathrm{C} 13.7$ & \\
\hline & M2 & Iya, satu aja & C13.9 & \\
\hline \multirow{4}{*}{$\begin{array}{c}\text { Kualitas } \\
\text { Tempat } \\
\text { Pelelangan Ikan }\end{array}$} & G1 & $\begin{array}{l}\text { ada keterbatasan yang belum } \\
\text { bisa diukur secara margin } \\
\text { secara ekonomi itu ada } \\
\text { beberapa kendala disitu } \\
\text { belum termanfaatnya tempat }\end{array}$ & $\mathrm{T} 2.1$ & \multirow{4}{*}{$\begin{array}{lr}\text { Terkonfirmasi } & \text { bahwa } \\
\text { kualitas Tempat } & \text { Than } \\
\text { Pelelangan Ikan atau TPI } \\
\text { sebagai sarana dalam } \\
\text { pengendalian produksi } \\
\text { berupa pendataan hasil } \\
\text { produksi belum } \\
\text { termanfaatkan walaupun } \\
\text { ada. Sehingga TPI } \\
\text { menjadi penyebab } \\
\text { sedikitnya sumbangan } \\
\text { sector perikanan terhadap } \\
\text { PDB. }\end{array}$} \\
\hline & & Sebenarnya pengaruhnya & & \\
\hline & & $\begin{array}{l}\text { adalah untuk mendata } \\
\text { produksi secara maksimal itu }\end{array}$ & & \\
\hline & G1 & $\begin{array}{l}\text { diperlukan, pada saat dia } \\
\text { mendarat tentunya akan } \\
\text { melakukan bongkar ikan }\end{array}$ & $\mathrm{T} 2.2$ & \\
\hline
\end{tabular}

\section{a. Faktor Pendorong Pengembangan Agribisnis Perikanan Tangkap Berdasarkan}

\section{Variabel}

Adapun faktor-faktor yang mendorong pengembangan agribisnis perikanan tangkap di kabupaten Penajam Paser Utara pada masing-masing subsistem diantaranya subsistem pengadaan, subsistem proses produksi, subsistem agroindustri dan pengolahan hasil, subsistem pemasaran dan subsistem penunjang. Terdapat 21 variabel sebagai faktor pendorong pengembangan agribisnis perikanan tangkap berdasarkan persepsi 3 stakeholder terpilih yaitu Dinas Perikanan Kabupaten PPU, Kelompok Perikanan KUB, dan Kelompok Perikanan POKLAHSAR. Hal tersebut berarti bahwa semua variabel penelitian yang telah 
ditemukan dalam teori merupakan faktor pendorong pengembangan agribisnis perikanan tangkap diantaranya kualitas kapal penangkapan ikan, jumlah kapal penangkapan ikan, kualitas alat penangkapan ikan, jumlah alat penangkapan ikan, komoditas, industri makanan, pengeringan, pembekuan, kualitas pasar tradisional, jumlah pasar tradisional, jumlah pemasar ikan/tengkulak, kualitas lembaga keuangan, jumlah lembaga keuangan, kualitas lembaga penyuluh, jumlah lembaga penyuluh, kualitas lembaga pemerintah, jumlah lembaga pemerintah, kualitas transportasi, jumlah transportasi, kualitas koperasi agribisnis dan jumlah koperasi agribisnis.

\section{b. Faktor Penghambat Pengembangan Agribisnis Perikanan Tangkap Berdasarkan Variabel}

Adapun faktor-faktor yang menghambat pengembangan agribisnis perikanan tangkap di kabupaten Penajam Paser Utara pada masing-masing subsistem diantaranya subsistem pengadaan, subsistem proses produksi, subsistem agroindustri dan pengolahan hasil, subsistem pemasaran dan subsistem penunjang. Terdapat 4 variabel sebagai faktor penghambat pengembangan agribisnis perikanan tangkap berdasarkan persepsi 3 stakeholder terpilih yaitu Dinas Perikanan Kabupaten PPU, Kelompok Perikanan KUB, dan Kelompok Perikanan POKLAHSAR. Adapun variabel tersebut diantaranya teknik pengeringan, jumlah lembaga penyuluh, kualitas koperasi agribisnis, dan kualitas Tempat Pelelangan Ikan.

\section{c. Hasil Identifikasi Faktor Pendorong dan Faktor Penghambat Pengembangan Agribisnis Perikanan Tangkap}

Berdasarkan hasil analisis faktor pendorong dan faktor penghambat yang dilihat dari persepsi stakeholder dan kondisi eksisting didapatkan bahwa sebanyak 21 variabel merupakan faktor pendorong pengembangan agribisnis perikanan tangkap diantaranya kualitas kapal penangkapan ikan, jumlah kapal penangkapan ikan, kualitas alat penangkapan ikan, jumlah alat penangkapan ikan, komoditas, industri makanan, pengeringan, pembekuan, kualitas pasar tradisional, jumlah pasar tradisional, jumlah pemasar ikan/tengkulak, kualitas lembaga keuangan, jumlah lembaga keuangan, kualitas lembaga penyuluh, jumlah lembaga penyuluh, kualitas lembaga pemerintah, jumlah lembaga pemerintah, kualitas transportasi, jumlah transportasi, kualitas koperasi agribisnis dan jumlah koperasi agribisnis. Namun diantara 21 Variabel yang menjadi faktor pendorong, terdapat kode dari jawaban responden 
yang menyebutkan kalimat yang menunjukkan bahwa variabel tersebut merupakan faktor penghambat pengembangan agribisnis diantaranya variabel pengeringan. Pada variabel pengeringan sebanyak 1 kode menyatakan bahwa dengan kondisi cuaca dapat menghambat produksi pengeringan ikan. Namun hal tersebut dapat diakali oleh pengolah yaitu dengan merendam terlebih dahulu di air garam agar mengurangi resiko kebusukan ikan. Sehingga walaupun pengeringan terhambat karena cuaca, hal tersebut tidak menjadi masalah sehingga pengeringan tetap dapat menjadi faktor pendorong pengembangan agribisnis perikanan tangkap. Selanjutnya pada variabel jumlah lembaga penyuluh sebanyak 1 kode menyatakan bahwa dengan jumlah 1 penyuluh pada setiap Kecamatan dirasa kurang. Namun walaupun demikian, penyuluh dirasa masih mampu untuk memberikan penyuluhan di masing-masing Kecamatan dengan baik, sehingga variabel jumlah lembaga penyuluh masih mampu untuk menjadi faktor pendorong dalam pengembangan agribisnis perikanan tangkap. Selanjutnya pada variabel kualitas koperasi agribisnis terdapat 1 kode yang menyatakan sebagai faktor penghambat karena pelayanan yang diberikan belum mencakup layanan simpan pinjam, namun hal tersebut tidak menjadi masalah serius karena pihak koperasi sedang melakukan pengajuan proposal untuk pencairan dana yang kemudian dapat dialokasikan sebagai simpan pinjam bagi nelayan. Sehingga variabel kualitas koperasi agribisnis tetap dapat menjadi faktor pengembangan agribisnis perikanan tangkap.

Untuk variabel kualitas Tempat Pelelangan Ikan atau TPI yang merupakan faktor penghambat pengembangan agribisnis perikanan tangkap dapat dilihat dari kondisinya yang memang ada di Kecamatan Waru namun belum termanfaatkan. Sehingga untuk kualitas TPI perlu dilakukan upaya peningkatan kualitas dengan cara memanfaatkan lokasi TPI yang telah ada dengan mengacu pada standar terkait pengadaan TPI yang ada pada Pangkalan Pendaratan Ikan PPI dengan kriteria menurut Peraturan Menteri Kelautan dan Perikanan Tentang Kepelabuhanan Perikanan Tahun 2012 adalah sebagai berikut.

1. Mampu melayani kapal perikanan yang melakukan kegiatan perikanan di perairan Indonesia,

2. Memiliki fasilitas tambat labuh untuk kapal perikanan berukuran sekurangkurangnya 5 GT,

3. Panjang dermaga sekurang-kurangnya $50 \mathrm{~m}$, dengan kedalaman kolam sekurangkurangnya minus $1 \mathrm{~m}$,

4. Mampu menampung kapal perikanan sekurang-kurangnya 15 unit atau jumlah keseluruhan sekurang-kurangnya 75 GT, 
Jurnal Planologi Vol. 18 No. 1, April 2021

5. Memanfaatkan dan mengelola lahan sekurang-kurangnya 1 ha.

6. Terdapat aktivitas bongkar muat ikan dan pemasaran hasil perikanan rata-rata 2 ton per hari.

Berdasarkan kriteria tersebut diatas, PPI yang ada di Kecamatan Waru belum mampu memenuhi kriteria pada poin 1, 3. 5 dan 6. Hal tersebut dibuktikan dengan kondisi eksisting yang memang terdapat bangunan PPI namun tidak terdapat kegiatan. Sehingga bangunan tersebut kerap kali digunakan sebagai tempat untuk penyuluhan saja.

Sehingga dapat disimpulkan bahwa hasil dari analisis faktor pendorong dan penghambat adalah terdapat variabel kapal penangkapan ikan, alat penangkapan ikan, komoditas, industri makanan, pengeringan, pembekuan, pasar tradisional, lembaga keuangan, lembaga penyuluh, lembaga pemerintah, transportasi dan koperasi agribisnis sebagai faktor pendorong dalam pengembangan agribisnis perikanan tangkap.

\section{KESIMPULAN DAN SARAN}

\section{a. Kesimpulan}

Sebanyak 21 variabel penelitian terkonfirmasi sebagai faktor pendorong pengembangan agribisnis perikanan tangkap diantaranya kualitas kapal penangkapan ikan, jumlah kapal penangkapan ikan, kualitas alat penangkapan ikan, jumlah alat penangkapan ikan, komoditas, industri makanan, pengeringan, pembekuan, kualitas pasar tradisional, jumlah pasar tradisional, jumlah pemasar ikan/tengkulak, kualitas lembaga keuangan, jumlah lembaga keuangan, kualitas lembaga penyuluh, jumlah lembaga penyuluh, kualitas lembaga pemerintah, jumlah lembaga pemerintah, kualitas transportasi, jumlah transportasi, kualitas koperasi agribisnis dan jumlah koperasi agribisnis. Selain itu ditemukan adanya faktor penghambat diluar variabel yang terkonfirmasi dari transkrip wawancara stakeholder yaitu kualitas TPI atau Tempat Pelelangan Ikan. Sehingga untuk mendukung pendapatan daerah harus dilakukan perbaikan kualitas TPI yang telah ada di Kecamatan Waru.

\section{b. Saran}

Bagi peneliti selanjutnya dapat melakukan penentuan kriteria pemilihan stakeholder secara objektif agar tercapainya tujuan dari penelitian salah satunya dalam melakukan analisis content. Perlu adanya penjabaran kriteria yang lebih spesifik pada pemilihan stakeholder agar jawaban yang didapatkan mewakili jawaban dari populasi. 
Jurnal Planologi Vol. 18 No. 1, April 2021

Available: http://jurnal.unissula.ac.id/index.php/psa

\section{DAFTAR PUSTAKA}

Arbani, R, I. (2017), Strategi Revitalisasi Kawasan Sungai Kalimas Di Surabaya Utara, Skripsi, Jurusan Perencanaan Wilayah dan Kota, Institut Teknologi Sepuluh November, Surabaya

Arianto, I, K., dkk. (2016), Faktor-Faktor Yang Mempengaruhi Petani Kakao Bermitra Dengan Pt Mars (Studi Kasus Di Desa Cendana Hijau Kecamatan Wotu Kabupaten Luwu Timur), “Jurnal Pertanian Berkelanjutan (PERBAL), Vol. 4, No. 2, hal. 1-13

Dewi, I, A, L., dkk. (2015), Faktor-Faktor Pendorong Alihfungsi Lahan Sawah Menjadi Lahan Non-Pertanian (Kasus: Subak Kerdung, Kecamatan Denpasar Selatan), “Jurnal Manajemen Agribisnis, Vol. 3, No. 2, hal. 163-171

Diinillah, S, A. (2017), Pengembangan Ruang Terbuka Hijau Publik Di Kota Malang Melalui Program Corporate Social Responsibility (CSR), Skripsi, Departemen Perencanaan Wilayah dan Kota, Institut Teknologi Sepuluh November, Surabaya

Fauzi, D., dkk. (2016), Strategi Pengembangan Agribisnis Kentang Merah di Kabupaten Solok, “Jurnal Agraris, Vol. 2, No. 1, hal. 87-96

Furqon, C. (2014), Analisis Manajemen Dan Kinerja Rantai Pasokan Agribisnis Buah Stroberi Di Kabupaten Bandung, “Jurnal Riset Manajemen, Vol. III, No.2, hal. 109-126 Hastuti, D, R, D. (2017), Ekonomika Agribisnis (Teori dan Kasus). Cetakan I. Perpustakaan Nasional, Katalog dalam terbitan (KDT). Makassar

Hermawan, R. (2006), Membangun Sistem Agribisnis. Seminar Mahasiswa Universitas Gadjah Mada. 20 Desember. Yogyakarta

Intyas, C, A., Zainal, A. (2013), Manajemen Agribisnis Perikanan, UB Pres, Malang Koestiono, D., Hardana, E, A. (2018), Sistem Agribisnis, Universitas Brawijaya, Malang

Koisine, H, Y., dkk. (2019), Faktor-Faktor Yang Mempengaruhi Produksi Tomat Di Desa Claket, Kecamatan Pacet, Kabupaten Mojokerto, “Jurnal Ilmiah Sosio Agribis, Vol.19, No. 1, hal. 53-66

Kusnadi, dkk, N., Ratna ,W., Dwi, R., Tintin, S., (2016), Dasar-Dasar Agribisnis, Edisi 2, Universitas Terbuka, Tangerang

Kriyantono, R. (2006), Teknik Praktis Riset Komunikasi, Kencana : Jakarta

Lubis, J., dkk. (2012), Analisis Faktor-faktor Yang Mempengaruhi Produksi Padi di Kabupaten Langkat, “Jurnal Agribisnis Sumatera Utara, Vol. 5, No.1, hal. 1-9 
Jurnal Planologi Vol. 18 No. 1, April 2021 Available: http://jurnal.unissula.ac.id/index.php/psa

Nainggolan, H, L., Johndikson A. (2012), Pengembangan Sistem Agribisnis Dalam Rangka Pembangunan Pertanian Berkelanjutan. Makalah. Seminar Nasional Pertanian Presisi Menuju Pertanian Berkelanjutan Universitas HKBP Nommensen. 3 April. Medan

Rasmikayati, E., dkk. (2017), Kajian Karakteristik, Perilaku Dan Faktor Pendorong Petani Muda Terlibat Dalam Agribisnis Pada Era Pasar Global, “Jurnal Pemikiran Masyarakat Ilmiah Berwawasan Agribisnis, Vol 3, No. 2, hal. 134-149

Yasmin, A., dkk. (2017), Analisis Faktor-Faktor Yang Mempengaruhi Mahasiswa Untuk Berwirausaha (Studi Kasus Mahasiswa Agribisnis UIN Syarif Hidayatullah Jakarta), “Jurnal Agribisnis, Vol. 11, No. 7, hal. 202 - 217 